\title{
A Catalytic Study of the Modified Coal Gasification Process to Produce Clean Hydrogen Gas
}

\author{
Sushant Kumar*, Vadym Drozd, and Surendra K Saxena \\ Center for the Study of Matter at Extreme Conditions, College of Engineering and Computing, \\ Florida International University, Miami, FL 33199. * corresponding author.
}

doi:10.5618/chem.2011.v2.n1.3 || Received: 21-03-2012, Accepted: 13-04-2012, Available online: 15-04-2012

\begin{abstract}
A catalytic study was performed on the following proposed modified coal gasification reaction:

$\mathrm{NaOH}(\mathrm{s})+\mathrm{C}(\mathrm{s})+\mathrm{H}_{2} \mathrm{O}(\mathrm{g})=\mathrm{Na}_{2} \mathrm{CO}_{3}(\mathrm{~s})+\mathrm{H}_{2}(\mathrm{~g})$.

Our study reveals that in the presence of $2 \mathrm{~h}$ ball milled Raney nickel (average crystallite size of 209 $\AA)$ this reaction is completed at $500{ }^{\circ} \mathrm{C}$ in 120 minutes. $\mathrm{X}$-ray diffraction technique is used for the characterization of the catalysts. Catalyst's surface morphology is analysed by using scanning electron microscope. From a study of the surface morphology and activity of the used catalysts, a direct correlation of coal particle size with the reaction kinetics has been established. The findings reveal that the globular particles have better catalytic effect than flaky disk shaped particles.
\end{abstract}

Keywords: coal gasification; crystallite size; reaction kinetics; catalysts; X-ray diffraction; Scanning electron microscope.

\section{Introduction}

The currently used industrial method of hydrogen production (the Steam-methane-reformation) requires emission of several tonnes of carbon dioxide for each tonne of hydrogen and therefore, is not helpful to the environment. The solution to this problem is still under research. So far, the suggested methods are either expensive or are in their early stages. Various alternate schemes have been proposed to curb $\mathrm{CO}_{2}$ emission and overcome kinetic barriers with the use of $\mathrm{CO}_{2}$ adsorbing solids and catalysts [1-8]. However, to achieve the benefits of a truly sustainable hydrogen energy economy, few researchers [9-11] have suggested the production of hydrogen from non-fossil resources. But the associated cost is several times higher than that produced from fossil fuels.
We have demonstrated that the inclusion of sodium hydroxide in the steam-methane-reformation or coal gasification reactions lowers the reaction temperature and produces a carbonate $[6,12]$.

$$
\begin{gathered}
2 \mathrm{NaOH}(\mathrm{s})+\mathrm{C}(\mathrm{s})+\mathrm{H}_{2} \mathrm{O}(\mathrm{g})=\mathrm{Na}_{2} \mathrm{CO}_{3}(\mathrm{~s})+2 \mathrm{H}_{2}(\mathrm{~g}) \\
\Delta \mathrm{H}=64.58 \mathrm{~kJ}(600 \mathrm{~K}) \\
\mathrm{C}(\mathrm{s})+2 \mathrm{H}_{2} \mathrm{O}(\mathrm{g})=\mathrm{CO}_{2}(\mathrm{~g})+2 \mathrm{H}_{2}(\mathrm{~g}) \\
\Delta \mathrm{H}=95.73 \mathrm{~kJ}(600 \mathrm{~K})
\end{gathered}
$$

Reaction (2) is a well established coal gasification process. This process is operated between 500 and 1200 ${ }^{0} \mathrm{C}$ in gasifiers. Gasifiers use steam, oxygen and/or air and produce a mixture of $\mathrm{CO}_{2}, \mathrm{CO}, \mathrm{H}_{2}, \mathrm{CH}_{4}$ and $\mathrm{H}_{2} \mathrm{O}$. Carbon monoxide gas is further processed by the shiftgas reaction to produce hydrogen with evolution of $\mathrm{CO}_{2}$. However, modified coal gasification reaction (here, reaction (1)) uses sodium hydroxide as a reactant which not only reduces the amount of required heat but also sequesters $\mathrm{CO}_{2}$ gas.

Sodium hydroxide has been employed as a reactant to facilitate various reactions which are involved in the hydrogen gas production. Reichman et al. [13] suggested a process called Ovonic renewable hydrogen (ORH). This method involves sodium hydroxide for the reformation of organic matter to produce hydrogen gas. While, William et al. [14] used sodium hydroxide as a promoter to produce hydrogen gas via hydrothermal gasification of glucose and other biomass sample. Kamo et al. [15] pyrolyzed dehydrochlorinated polyvinyl chloride (PVC) and activated carbon with sodium hydroxide and steam to generate hydrogen gas and sodium carbonate with methane, ethane and carbon dioxide as byproducts.

In our proposed reaction, we used sodium hydroxide as a reactant, which when react with the products of coal and steam reaction forms sodium carbonate and evolves 
clean hydrogen gas. Our previous work [6] successfully demonstrated the feasibility of this reaction and requires an inexpensive and efficient catalyst in this system.

Nickel and Raney nickel are highly active and widely employed as catalysts for various industrial processes [16-20]. Numerous studies have confirmed the significant role of catalysts geometric factor, electronic factor and surface imperfections in determining their catalytic activity [21-27]. Therefore, it is always reasonable to explore the possible relation between the catalyst grain size and the reaction rate.

Here, we obtained different sized coal and catalysts particles using mechanical milling. Mechanical milling is regarded as one of the simple and common methods to obtain uniform distribution of composition. During mechanical process, powder particles undergo severe deformation which leads to various crystal defects such as lattice strains, dislocations, vacancies and morphological changes [28-30]. In this work, our focus is to study the catalytic behaviour of different sized and shaped catalysts and also to learn about the effect of using variously ball milled coal with this reaction.

\section{Materials and Methods}

2.1 Catalysts preparation. The catalysts used for reaction (1) are nickel and Raney nickel. Nickel Powder (-100 mesh), Raney nickel (-325 mesh) were delivered by Sigma Aldrich and Acros Organics respectively. A planetary Retsch PM100 ball milling machine has been used to reduce the particle sizes of these catalysts. The cylindrical ball milling container has an internal diameter and length of 1.6" each. The powder to ball weight ratio was $1 / 54$. Milling time varied from 1 to $4 \mathrm{~h}$ but the revolution speed $(250 \mathrm{rpm})$ remained the same.

2.2 Catalyst Characterization. X-ray diffraction patterns for different catalysts were obtained using Bruker GADDS/D8 X-ray system with Apex Smart CCD Detector and Mo direct-drive rotating anode (50 $\mathrm{kV} ; 20 \mathrm{~mA}$ ). Jeol JSM-5910-LV and Jeol JSM-6330F scanning electron microscope were used to study the surface morphology of the catalysts.

Image $\mathbf{J}$ software was used to determine the average particle sizes of both coal and Raney nickel catalysts. A total of nearly 50 particles were taken into consideration from 3-4 different SEM images to ensure a precise estimation of the average particle sizes.

2.3 Reaction Study. About 0.1 gm of anhydrous sodium hydroxide (Sigma Aldrich (98\% purity)) was homogeneously mixed with a stoichiometric amount of anthracite coal in an alumina boat (reaction 1). The alumina boat was then positioned at the hot spot of an alumina tubular furnace of 18.5" length and .667" diameter. Thereafter, the furnace temperature was increased. Nitrogen gas was employed at $50 \mathrm{ml} / \mathrm{min}$ during rise in temperature. Once the required temperature was attained, steam was allowed to pass through the alumina tube. It should be noted that steam flow rate has not been controlled in this study. The catalysts were added in an amount of 3 wt. \% of initial weight of $\mathrm{NaOH}$. A higher amount of catalysts, if added, will increase the process cost while a lower amount will not be sufficient enough to accelerate the reaction as desired.

The extent of reaction was analyzed by calculating the exact amount of sodium carbonate formed via reaction (1). The mixture of product and un-reacted reactant were titrated against a strong acid. The equivalent points were detected by using acid-base indicators (Phenolphthalein and Methyl Orange). The below reaction confirms the formation of sodium bicarbonate during titration. However, sodium bicarbonate does not form during reaction.

$$
\mathrm{Na}_{2} \mathrm{CO}_{3}+\mathrm{HNO}_{3} \longrightarrow \mathrm{NaHCO}_{3}+\mathrm{HNO}_{3}
$$

and then

$$
\mathrm{NaHCO}_{3}+\mathrm{HNO}_{3} \longrightarrow \mathrm{NaNO}_{3}+\mathrm{CO}_{2}+\mathrm{H}_{2} \mathrm{O}
$$

\section{Results and Discussion}

\subsection{Characterization of Catalysts}

3.1.1 Catalysts Crystallite Size. The crystallite size of these particles was calculated using Scherrer's formula [31]. The Scherrer equation describes the relationship between mean crystallite size and diffraction line width. The equation used here is

$$
D=\frac{0.9 \lambda}{\left(\beta-\beta_{0}\right) \operatorname{Cos} \theta}
$$

Where, $\lambda$ is the wavelength of $\mathrm{X}$-ray radiation (Mo $\left.\mathrm{K} \alpha_{1}=0.7093171 \dot{\mathrm{A}}\right), \beta$ the width at half maximum intensity of a peak, $\beta_{0}$ the width at half maximum of highly crystalline material $\mathrm{LaB}_{6}$ and $\theta$ the Bragg angle, half of the diffractometer angle. The crystallite size signifies the size of coherently diffracting domain and it cannot be always regarded as particle size due to the presence of polycrystalline aggregates.

Figure 1 illustrates the x-ray diffraction pattern for variously ball milled Raney nickel catalysts. The crystallite sizes for raw, 1, 2 or $4 \mathrm{~h}$ ball milled Raney nickel are 413, 347, 209 and $190 \AA$ respectively. It can be seen that as the crystallite sizes decreased due to ball milling, diffraction peaks shift towards the low angle direction and peak widths increase. During the prolonged ball milling time, the energy produced by ball 


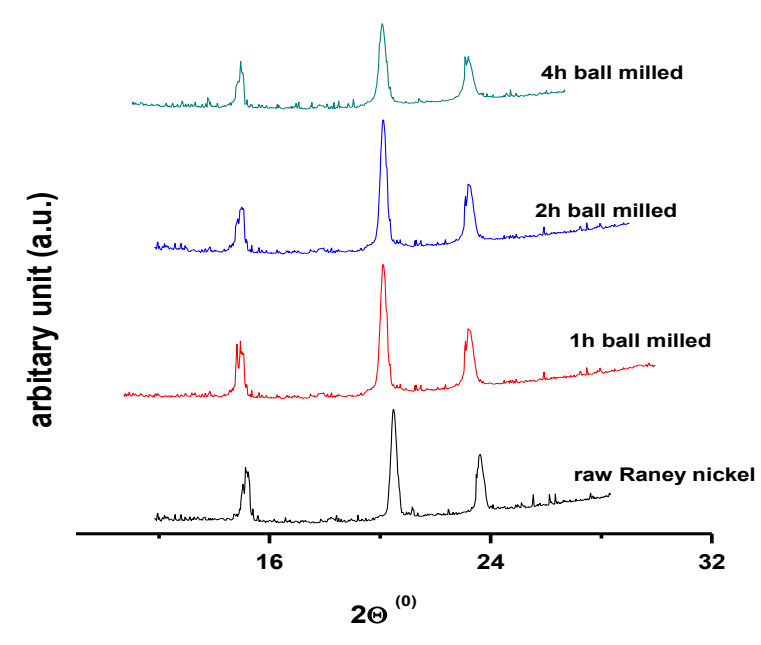

Figure 1 X-ray diffraction pattern for variously ball milled Raney nickel.

milling drastically increases the strain rate and causes several modifications like vacancies, atomic site interchanges and dislocations [22,32-33]. However, Raney nickel nullifies the chance of any atomic site interchange but the possibility of formation and movement of dislocations can not be denied. According to Fetch, the generation and movement of dislocations could decrease grain size [34]. Here, it can be observed that for $2 \mathrm{~h}$ ball milled Raney nickel, there is relatively high $\%$ reduction in the crystallite sizes. This suggests that the mechanical milling caused an intensive deformation for $2 \mathrm{~h}$ ball milled Raney nickel catalysts powders.
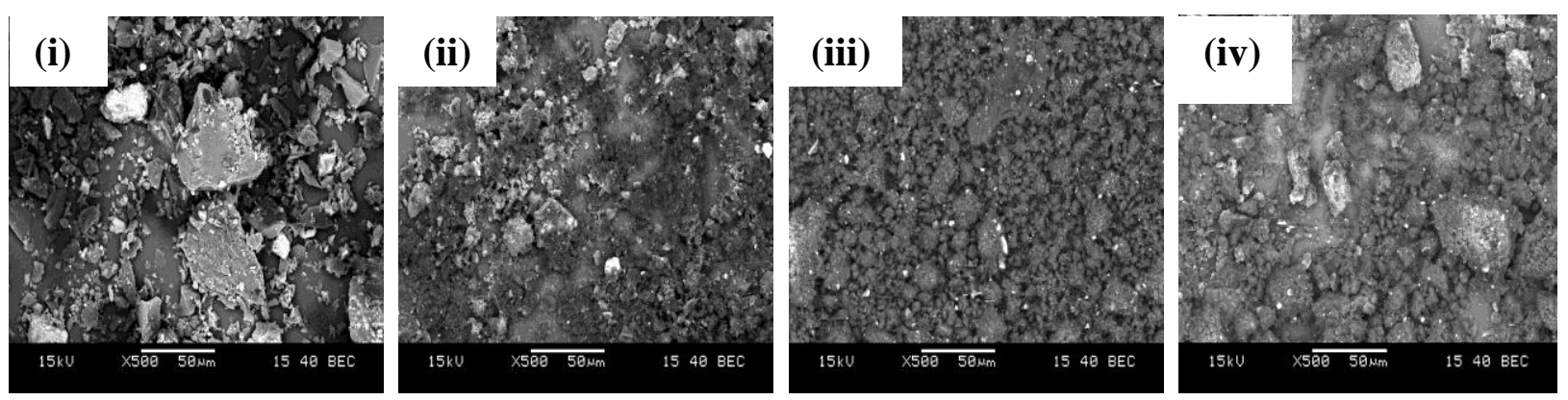

Figure 2 Back scattered SEM image of (i) without (ii) $1 \mathrm{hr}$ (iii) $2 \mathrm{~h}$ and (iv) $4 \mathrm{~h}$ ball milled coal

3.1.2 Morphology and particle size analysis. Figure 2 illustrates the back scattered scanning electron microscope images of variously milled coal particles. The mean particle size for raw, 1, 2 or $4 \mathrm{~h}$ ball milled coal is $15.07,9.29,6.27$ and $13.97 \mu \mathrm{m}$ respectively. The smallest coal particle size of $6.27 \mu \mathrm{m}$ was obtained by ball milling for $2 \mathrm{~h}$. But if the time of ball milling was extended to $4 \mathrm{~h}$, the particles agglomerated resulting in larger particle sizes.

The particle size measurement of Raney nickel catalysts followed the same procedure as for the coal particles. The average particle sizes of raw, 1, 2 and $4 \mathrm{~h}$ Raney nickel catalysts lie in the range of $10-20 \mu \mathrm{m}$. However, it can be observed that the surface morphology of these particles varied drastically over different ball milling periods. Initially, raw Raney nickel particles are almost spherical in shape and have a very wide distribution of the particle sizes. When this was milled for $1 \mathrm{~h}$, their spherical shape has been transformed into a flaky disk shape. Its formation could be due to the impact actions of the milling balls. However, when Raney nickel catalyst was ball milled for $2 \mathrm{~h}$ some of its flaky disk shaped particles transformed back to globular shape. These globular particles are formed by the agglomeration of the diskshaped particles by folding, enclosure, unfolding and pile-up [35]. Prolonged ball milling time caused severe attrition of these globular particles and retransformed them into disk shaped particles [Figure 3(i)]. 
(i)

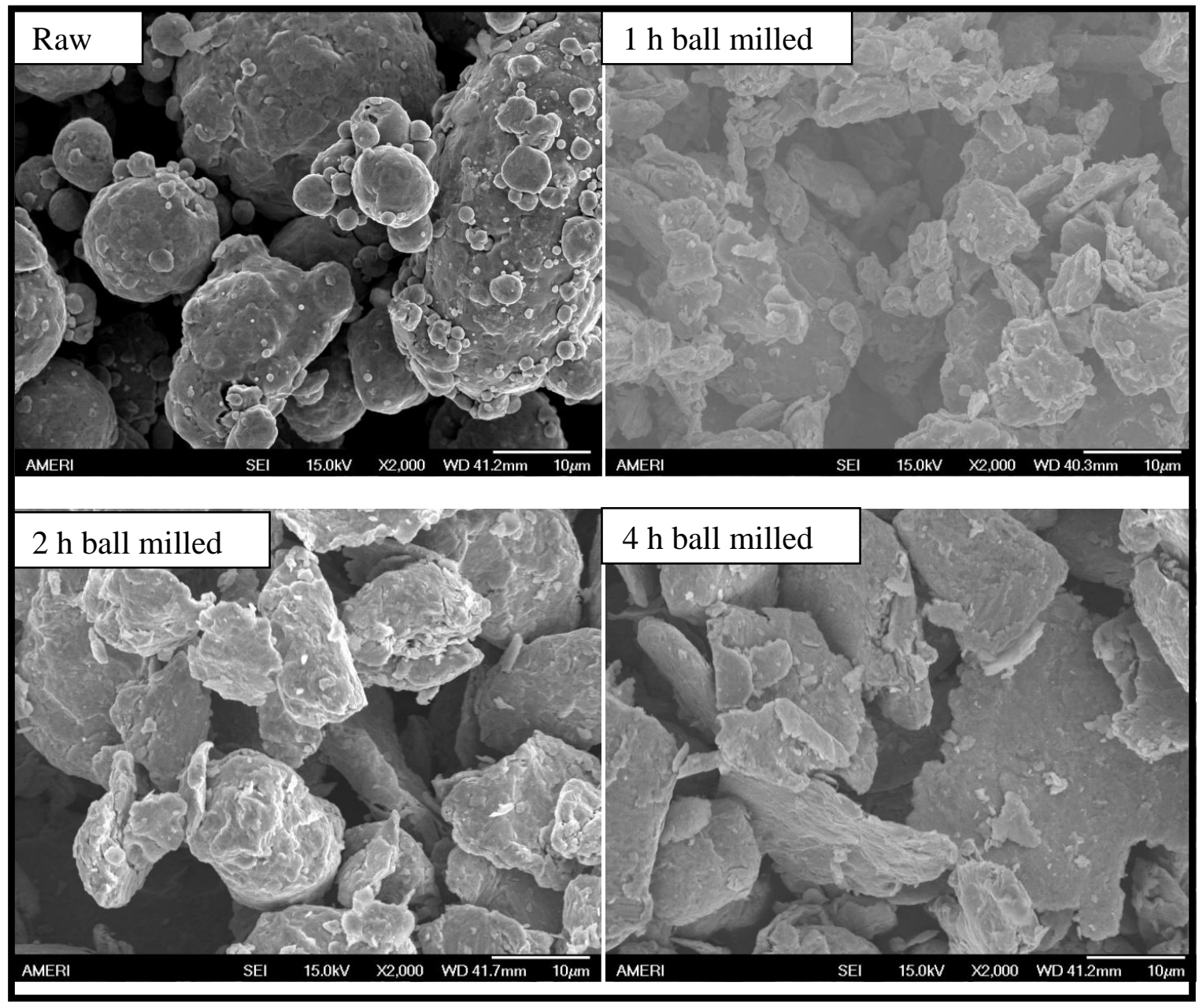

(ii)

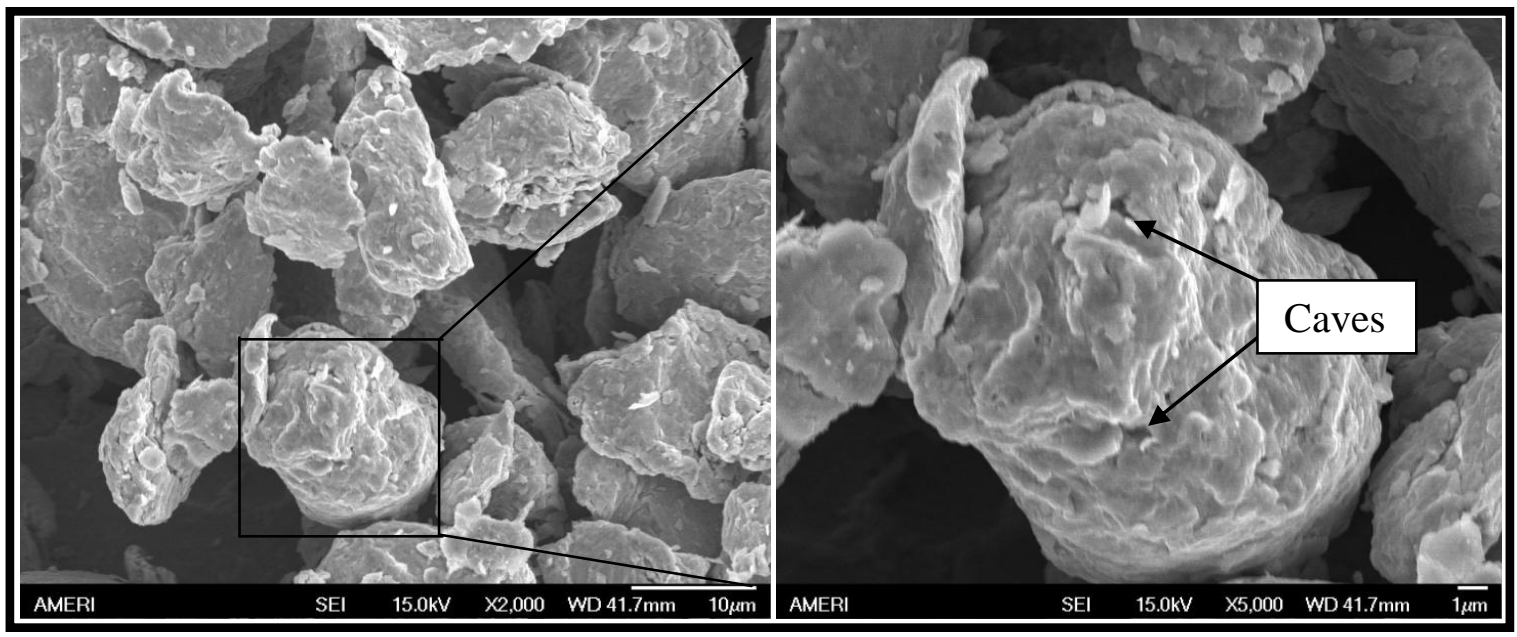

Figure 3 SEM images of (i) variously ball milled Raney nickel each at 2000X magnification (ii) $2 \mathrm{~h}$ ball milled Raney nickel showing caves at 5000x magnification. 
3.2 Reaction Results. Figure 4 shows x-ray diffraction patterns for the product which confirms the formation of sodium carbonate by reaction (1) in the presence of nickel catalysts at $600{ }^{\circ} \mathrm{C}$. Peak locations for $\mathrm{Ni}$, $\mathrm{Na}_{2} \mathrm{CO}_{3}$ were obtained from JCPDS \#70-0989 and 370451 respectively.

The experimental study of reaction (1) has been carried out at two different temperatures i.e. 500 and $600^{\circ} \mathrm{C}$. Figure 5 demonstrates the reaction rate at $600^{\circ} \mathrm{C}$ for various coal particle sizes. The graphs suggest that as the reaction time increased, formation of sodium carbonate also increased accordingly. However, the plot for $4 \mathrm{~h}$ ball milled coal shows a minute variation in the reaction yield at higher reaction times. The reason for this phenomenon lies in the surface morphology of coal particles. We note that as coal particle size increased, the reaction rate decreased accordingly.

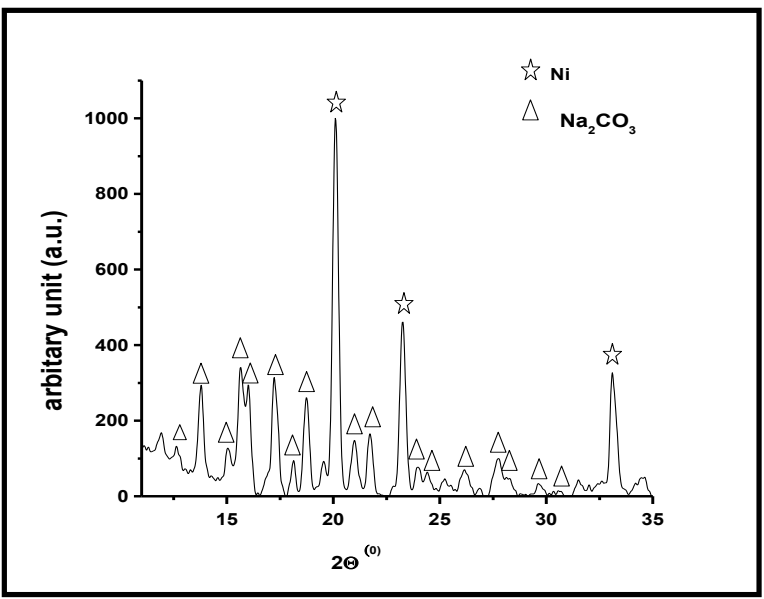

Figure 4 X-ray diffraction pattern confirms the product formation in the presence of nickel catalyst for reaction (1) at $600^{\circ} \mathrm{C}$.
The selectivity and activity of catalysts are often found to be largely dependent on the surface structure, particle morphology and size. In particular, the particle size is a critical issue as it determines the density of active sites. The catalytic study of $2 \mathrm{~h}$ ball milled coal (mean size of $6.27 \mu \mathrm{m}$ ) was performed using nickel metal powder (-100 mesh) and Raney nickel (-325 mesh) at $600^{\circ} \mathrm{C}$. In the presence of highly active Raney nickel catalysts, reaction has a faster rate [Figure 6 (i)]. Raney nickel possesses highly porous microstructure and thus has high surface area. However, nickel can also act as a catalyst for reaction (1) but its observed activity is relatively lower than that of Raney nickel. Here, the purpose was to explore the effect of different sized Raney nickel catalysts. Therefore, raw Raney nickel catalysts were ball milled for different times.

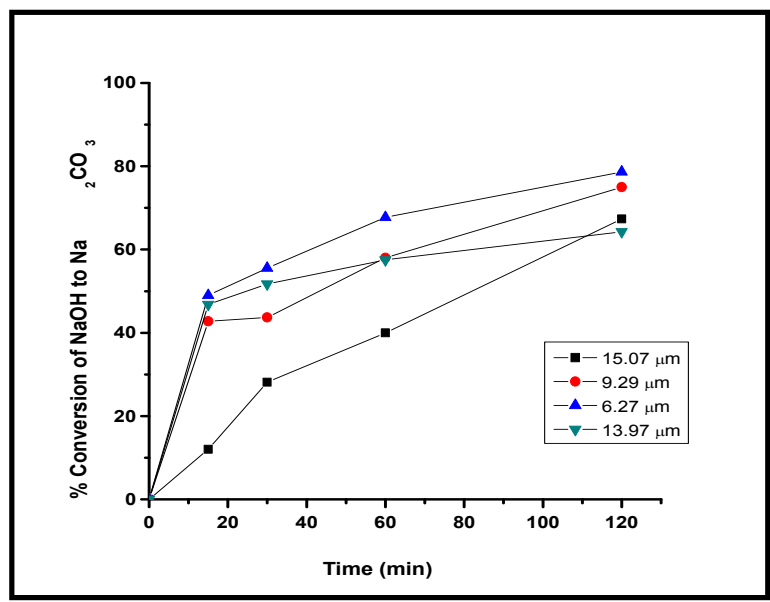

Figure $5 \%$ Conversion of $\mathrm{NaOH}$ to $\mathrm{Na}_{2} \mathrm{CO}_{3}$ for different sized coal particles at different time at $600^{\circ} \mathrm{C}$.
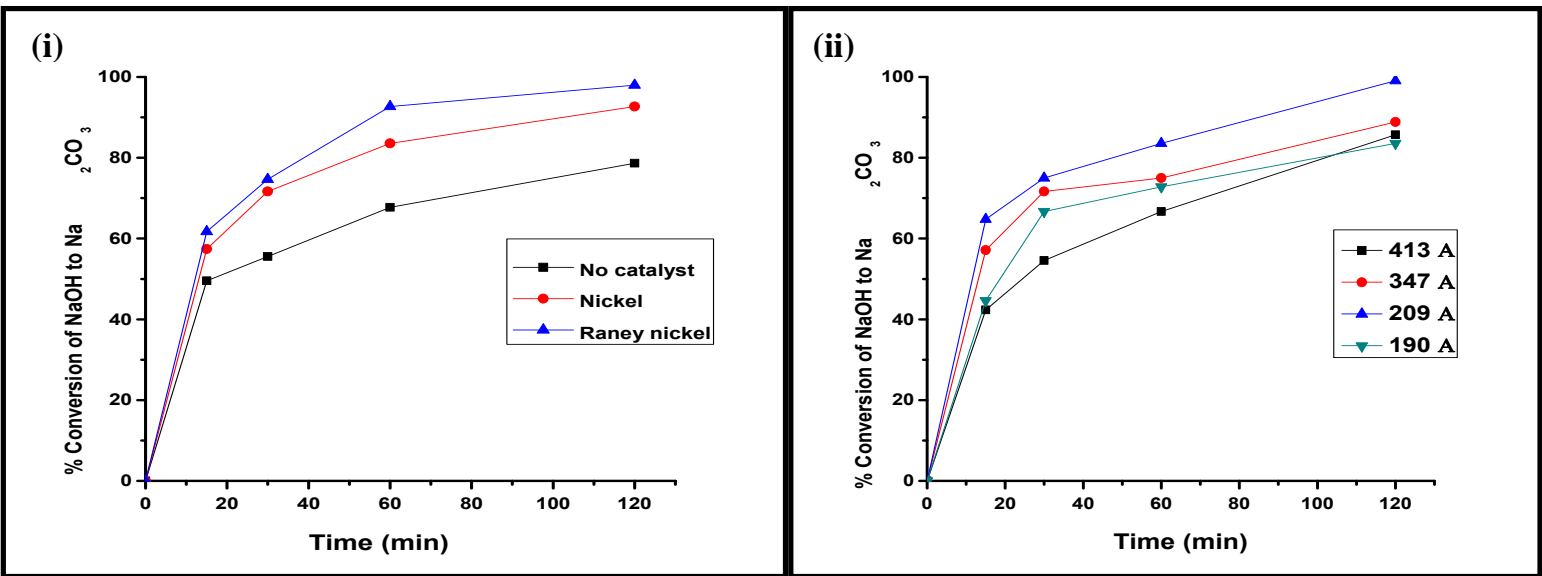

Figure 6 for (i) different catalysts at $600^{\circ} \mathrm{C}$ and (ii) different sized Raney nickel at $500^{\circ} \mathrm{C}$. 
Hydrogen generation curves for different sized Raney nickel at $500^{\circ} \mathrm{C}$ are plotted in Figure 6(ii). Results show that $2 \mathrm{~h}$ ball milled catalysts have the best effect compared to others. The reason for high catalytic activity of $2 \mathrm{~h}$ ball milled Raney nickel catalysts lie in the morphological as well as geometrical factors.SEM images in Figure 3 show the surface morphology of variously ball milled Raney nickel. Figure 3 (ii) demonstrates the presence of a large number of open caves for $2 \mathrm{~h}$ ball milled Raney nickel which could be the reason for its high efficiency. In summary, globular catalyst particles exhibit high catalytic activity compared to that of flaky disk shaped catalyst. The deactivation of $4 \mathrm{~h}$ ball milled Raney nickel can be due to either a high mechanical abrasion of the catalysts surface or thermally induced deactivation. Since high temperature existed during prolonged milling, most likely it caused the loss of catalytic surface area because of the growth of the crystallites of the catalytic phase. A poor catalytic activity of the disk shaped $1 \mathrm{~h}$ ball milled Raney nickel can be explained in a similar fashion. Here, shape of the catalysts has been transformed into globular to flaky disk. This could have led to closing of the open caves. However, during $2 \mathrm{~h}$ of ball milling, flaky disk shaped particles agglomerate and leave a large number of open pores. In addition to the morphological aspect of the catalysts, there is also a geometric factor which is contributing to the catalytic activity. The maximum \% reduction in the crystallite size was observed for $2 \mathrm{~h}$ milling time of Raney nickel catalysts. Thus, a large number of formations and movement of dislocations or vacancies have occurred which led to an increased activity for $2 \mathrm{~h}$ ball milled Raney nickel catalysts.

All the kinetic curves show a rapid increase in the yield after 30 minutes of the reaction. The obvious reason could be the formation of sodium carbonate as a product; which when formed in a sufficient amount speed up this reaction. Thus, sodium carbonate too possesses catalytic property and can be categorized as a catalyst for reaction (1).

Carbon monoxide has a high affinity for forming carbonyl compounds with the transition metals [36]. These carbonyl compounds can be readily decomposed back to the transition metals. Carbon monoxide passing over the catalysts surface may have been adsorbed and formed carbonyl compounds. These nickels based formed carbonyl compounds have increased the collision frequency of sodium hydroxide and carbon monoxide gas. As a result, higher \% conversion of $\mathrm{NaOH}$ to $\mathrm{Na}_{2} \mathrm{CO}_{3}$ was observed in the presence of nickel or Raney nickel catalysts.
Nickel has the least corrosion rates for molten sodium hydroxide. Nickel is essentially immune to caustic stress-corrosion cracking even in molten anhydrous sodium hydroxide at high temperatures. As concentration of sodium hydroxide and temperature increase during the evaporation process or during chemical- processing, the corrosivity enhances considerably. Likewise, increasing the nickel content of nickel-based alloys produces increasing resistance to general corrosion and stress-corrosion cracking in the caustic soda. Thus, a number of nickel-base alloys can be used for handling sodium hydroxide, depending on concentration and temperature [37]. Therefore, these properties of nickel ensure the longevity and high recyclability of nickel based catalysts applied in reaction (1).

\section{Conclusion}

Our earlier study demonstrated that reaction (1) is complete at $675^{\circ} \mathrm{C}$ in about an hour [6]. Here, we have successfully demonstrated the effect of various catalysts on this reaction and found their optimum size and shape. The reaction is completed in 120 minutes in the presence of $2 \mathrm{~h}$ ball milled Raney nickel catalyst at $500^{\circ} \mathrm{C}$. A direct correlation of coal particle size on the reaction rate has been established by this study. In addition, we also explored the effect of the surface morphology of Raney nickel. Globular particles exhibiting higher surface area and high open caves has better effect than flaky disk shaped particle.

\section{Acknowledgements}

We greatly acknowledge the financial support from CDAC (Carnegie/DOE alliance Center).

\section{References}

[1] Wang, H.Z.; Leung, D.Y.C.; Leung, M.K.H. Renewable \& Sustainable Energy Review, 2009, 13, 845-53. http://dx.doi.org/10.1016/j.rser.2008.02.009

[2] Ahmad, S.; Aitani, A.; Rahman, F.; Al-Dawood, A.; Al- Muhaish, F. Applied Catalysis A: Gen. 2009,359, $1-24$.

[3] Muradov, N. Int J Hydrogen Energy 2001, 26, 11651175. http://dx.doi.ora/10.1016/50360-3199(01)00073-8

[4] Kumar S., Saxena, S., Drozd V. A modified method for production of Hydrogen from Methane. Int. J. of Energy Research, 2011. http://dx.doi.ora/10.1002/er.1854

[5] Kalinci, Y.; Hepbasli, A.; Dincer, I. Int J Hydrogen Energy 2009, 34, 8799-8817.

http://dx.doi.ora/10.1016/i.ijhydene.2009.08.078

[6] Saxena, S.K.; Drozd, V.; Durygin, A. Int J Hydrogen Energy 2008, 33, 3625-3631. 
http://dx.doi.org/10.1016/j.ijhydene.2008.04.050

[7] Saxena, S.K.; Kumar, S.; Drozd, V. Int J Hydrogen Energy 2011, 36, 4366-4369.

http://dx.doi.org/10.1016/j.ijhydene.2010.12.133

[8] Muradov, N. Energy Fuels 1998, 12, 41-48.

http://dx.doi.org/10.1021/ef9701145

[9] Turner, J.A. Science 2004,305, 972-974. http://dx.doi.org/10.1126/science.1103197

[10] Sherif, S.A.; Barbir, F.; Veziroglu, T.N. Solar Energy 2005, 78,647-660.

http://dx.doi.org/10.1016/j.solener.2005.01.002

[11] Penner, S.S. Energy 2006, 31, 33-43. http://dx.doi.org/10.1016/j.energy.2004.04.060

[12] Saxena, S.K. Int J Hydrogen Energy 2003, 28, 4953. http://dx.doi.org/10.1016/50360-3199(02)00036-8

[13] Reichman, B; Mays, W.; Strebe, J.; Fetcenko, M. Int $J$ Hydrogen Energy 2010, 35, 4918-4924. http://dx.doi.org/10.1016/j.ijhydene.2009.08.097

[14] Onwudili, J.A.; Williams, P.T. Int J Hydrogen Energy 2009, 34, 5645-5656.

http://dx.doi.org/10.1016/j.ijhydene.2009.05.082

[15] Kamo, T.; Takaoka, K.; Otomo, J.; Takahashi, H. Fuel 2006, 85, 1052-1059.

http://dx.doi.org/10.1016/j.fuel.2005.10.002

[16] Pistonesi, C.; Juan, A.; Irigoyen, B.; Amadeo, N. Applied Surface Science 2007, 253, 4427-4437. http://dx.doi.org/10.1016/j.apsusc.2006.09.054

[17] Matsumura, Y.; Nakamori, T. Applied Catalysis A: Gen. 2004, 258,107-114.

http://dx.doi.org/10.1016/j.apcata.2003.08.009

[18] Hou, K.; Hughes, R. Chemical Engineering Journal 2001, 82, 311-328.

http://dx.doi.org/10.1016/S1385-8947(00)00367-3

[19] Numaguchi, T.; Shoji, K.; Yoshida S. Applied Catalysis A: Gen. 1995, 133,241-262. http://dx.doi.org/10.1016/0926-860X(95)00188-3

[20] Nozaki, T.; Muto, N.; Kado, S.; Okazaki, K. Catalysis Today, 2004, 89, 57-65. http://dx.doi.org/10.1016/j.cattod.2003.11.040

[21] Beeck. Adv. Catalysis 1950, 2, 151.

[22] Trapnell. Quart. Rev. 1954, 8, 494.

[23] Gregg. The surface chemistry of solids, chapter 2, Champan and Hall, 1961.

[24] Beeck. Rev.Mod. Physics 1945, 17, 61

[25] Couper; Eley. Disc Faraday Soc.1950, 8, 174

[26] Dowden; Reynolds. Disc Faraday Soc. 1950, 8, 184

[27] Hofer, E.M.; Hintermann, H.E. Trans. Faraday Soc.1964, 60, 1457-1465.

http://dx.doi.org/10.1039/tf9646001457

[28] Suryanarayan, C. Prog Mater Sci 2001, 46, 1-184. http://dx.doi.org/10.1016/50079-6425(99)00010-9

[29] Koch, C.C. Nanostruct Mater 1997, 9, 13-22. http://dx.doi.org/10.1016/50965-9773(97)00014-7

[30]Guerrero-Paz, J.; Jaramillo-Vigueras, D. Nanostruct Mater 1999, 11, 1123-1132. http://dx.doi.org/10.1016/509659773(99)00403-1

[31] Holzwarth, U.; Gibson, N. Nature Nanotechnology 2011, 6,534. http://dx.doi.org/10.1038/nnano.2011.145

[32] Zhou, L.Z.; Guo, J.T.; Jiang, T.D.; Wang, S.H. J Mater Sci Lett 1998, 17, 137-139.

http://dx.doi.org/10.1023/A:1006591018612

[33] Liang,G.; Huot, J.; Schulz, R. J Alloys Compd 2001, 320,133-139. http://dx.doi.org/10.1023/A:1006591018612

[34] Fecht, H.J. Nanostruct Mater 1995, 6, 33-42. http://dx.doi.org/10.1016/0965-9773(95)00027-5

[35] Lee, G.G.; Hashimoto, H.; Watanabe, R. Materials Transactions JIM 1995, 36,548-554.

[36] Zuckerman, J.J.; Atwood, D.J. Inorganic Reactions and Methods, Formation of Bonds to Transition and Inner-Transition Metals. New York: WILEY-VCH, 1998.

[37]Craig, D.B.; Anderson, D.S. Handbook of corrosion data, 2nd Edition, Ohio: ASM international, 2002. 